\title{
ROLE OF INTERLEUKIN-23 AS A MARKER OF DISEASE ACTIVITY IN RHEUMATOID ARTHRITIS PATIENTS
}

\section{Mazen M Al Sheikh*, Abeer M El-shafey*, Heba Hassan Gawish**, Enas Tawakal El desoky* \\ *Rheumatology\& Rehabilitation, **Clinical Pathology Departments, Zagazig University}

\section{ABSTRACT}

Background: Rheumatoid arthritis (RA) is a chronic autoimmune inflammatory disease. The pathogenesis of RA is mediated by an interdependent network of cytokines which has been extended to include the cytokine, IL-23. IL-23 production appears to be of great importance in the inflammatory reaction in RA. Objectives: We aimed in this study to estimate interleukin-23 (IL-23) level in the sera of rheumatoid arthritis (RA) patients and to determine its relation with disease activity.

Subjects and methods: This study was carried out on 40 patients with RA, and 40 healthy control subjects. RA disease activity was measured by 28 -joint disease activity score (DAS-28). All patients were subjected to full history taking, thorough clinical examination, radiological and laboratory investigations including c- reactive protein (CRP), erythrocyte sedimentation rate (ESR), rheumatoid factor (RF), anti cyclic-citrullinated peptide (anti-CCP) antibodies. Serum IL-23 was measured by enzyme-linked immunosorbent assay (ELISA).

Results: In RA patients serum IL-23 level was significantly elevated in comparison to the healthy controls $(\mathrm{p}<0.001)$. There was a significant positive correlations between IL-23 level and DAS 28 score. The highest level was detected in patients with high disease activity $(\mathrm{p}=0.03)$. There was statistically significant correlation between IL-23 levels and ESR, CRP, RF, anti-CCP antibodies.

Conclusion: IL-23 could be a useful marker for disease activity in RA.

Keywords: IL-23; Rheumatoid arthritis; DAS-28.

Corresponding author: Enas Tawakal El desoky, Mobile: 01028829223. E-mail address: enas tawakal1987 @ gmail.com.

\section{INTRODUCTION}

$\mathbf{R}^{\text {h }}$ heumatoid arthritis (RA) is an inflammatory autoimmune disease characterized by joint swelling, inflammation, progressive erosions and articular cartilage destruction leading to structural damage and permanent disability ${ }^{[1]}$. Cytokines play an important role in the processes that cause inflammation, articular destruction and extra-articular manifestations [2]. IL-23 is mainly secreted by activated macrophages and dendritic cells ${ }^{[3]}$. IL-23 is a proinflammatory cytokine responsible for maintaining balance between regulatory and effectors $\mathrm{T}$ - cell response, and it is an important factor for development of $\mathrm{T}$-cell dependent inflammatory response. IL-23 has a key role in chronic inflammation, which is a common characteristic of several autoimmune diseases through, two independent pathways. The first pathway is by the activation of Th17 cells and the second by the induction of the secretion of IL-17 by non-T cells ${ }^{[4]}$. IL-23 promotes Th17 cells producing IL-6, IL-17, IL-22, Tumour necrosis factor- $\alpha$ (TNF- $\alpha)$, and granulocyte-monocyte colony-stimulating factor $\quad(\mathrm{GM}-\mathrm{CSF})^{[2]}$. IL-23 has an essential role in other chronic autoimmune diseases as inflammatory bowel disease (IBD) ${ }^{[5]}$ and psoriasis ${ }^{[6]}$ and Behçet's disease ${ }^{[7]}$. In this study, we aimed to evaluate IL-23 level in the sera of RA patients in comparison to the healthy controls and to determine its relation with disease activity.

\section{Subjects and Methods}

This study was carried out in Rheumatology and Rehabilitation and Clinical Pathology Departments, Faculty of Medicine, Zagazig University Hospitals. Two groups were included in the study: group I included Forty patients (37 females and 3 males) with RA diagnosed according to 2010 American college of Rheumatology / European League Against Rheumatism (ACR/EULAR) classification criteria for $\mathrm{RA}^{[8]}$, group II included 40 healthy subjects (32 females and 8 males) taken as control matched for age and sex with the patients. Written consent was signed by the RA patients and healthy controls.

This study was approved by the institutional review board (IRB) of the faculty. Patients with other inflammatory autoimmune diseases, including systemic lupus erythromatosis (SLE), scleroderma, ankylosing spondylitis, psoriasis, Behcets 
disease and inflammatory bowel diseases were excluded from the study. Rheumatoid arthritis disease activity was evaluated by DAS$28^{[9]}$. All patients were subjected to full history taking, thorough clinical examination, radiological and laboratory investigations including complete blood count, erythrocyte sedimentation rate $(\mathrm{ESR})^{[10]}$, CRP was detected by immunohistochemistry, rheumatoid factor (RF) by nephelometry method, using automated analyzer and anticyclic citrullinated peptide ( anti-CCP) antibodies $^{[11]}$. Measurement of serum interleukin-23 level was performed by a commercial enzyme-linked immune sorbent assay (ELISA) kit for RA patients and controls. According to the instruction of the manufacturer by Sun Red international trade company, Shanghai, China. Serum samples were collected from patients on the same day of examination.

\section{STATISTICAL ANALYSIS}

The collected data were computerized and statistically analyzed using SPSS program (Statistical Package for Social Science) version 18.0.

\section{RESULTS}

Demographic data of RA patients and healthy controls included in the study:

RA patient's ages ranged between 23-62 years with a mean of $43.25 \pm 10.44$, while the control subjects ages ranged between $18-65$ years with a mean of $39.5 \pm 12.65$. There was no statistically significant difference between the two groups as regards age, sex distribution or number of smokers (table1).

Table (1): Demographic data of the two studied groups:

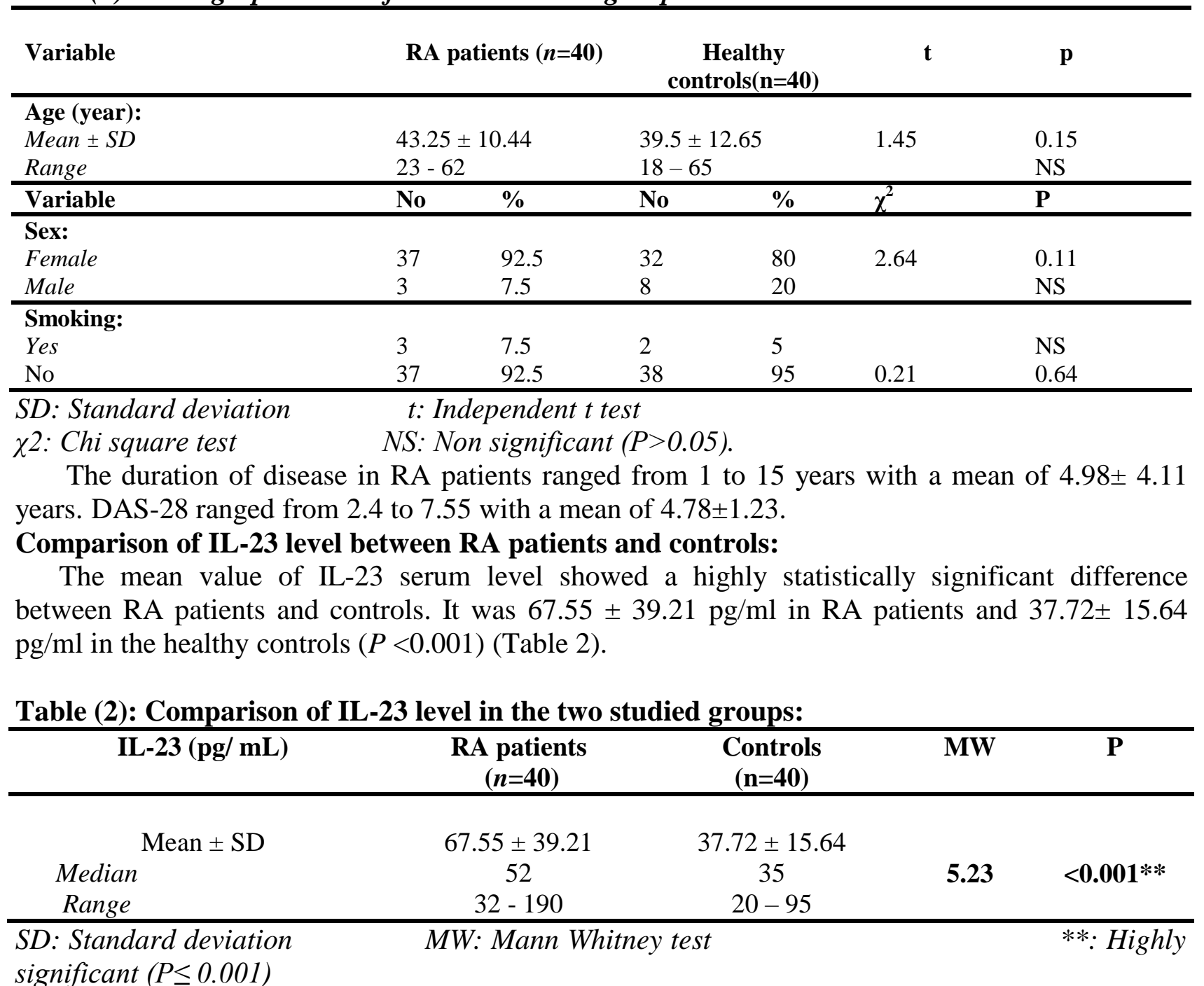

Comparison of serum IL-23 level in RA patients with different grades of DAS28: 
There was a statistically significant difference in IL-23 level between RA patients with different grades of DAS28. The highest level was detected in patients with high disease activity (Table 3).

Table (3): Comparison of serum IL-23 level in RA patients with different grades of DAS-28

\section{IL-23 level}

Disease activity

$\operatorname{Low}(n=4)$

$$
\text { (DAS28 } \leq 3.2 \text { ) }
$$

Moderate $(\mathbf{n}=\mathbf{2 3})$

$(3.2<$ DAS $28 \leq 5.1)$

High $(\mathbf{n}=13)$

(DAS28 > 5.1)

K $\quad \mathbf{P}$

Mean \pm SD $\quad$ Median

$\begin{array}{llll}43.5 \pm 7.37 & 43 & & \\ 64 \pm 33.05 & 52 & \mathbf{6 . 1 4} & \mathbf{0 . 0 3 *}\end{array}$

$\frac{81.23 \pm 50.6173}{K: \text { Kruskal Wal }}$

Correlation between serum IL-23 level, clinical and laboratory parameters of RA patients: There was statistically significant positive correlations between IL-23 level and DAS-28. Also, there was statistically significant positive correlation between serum IL-23 level and CRP, ESR, RF and anti CCP antibodies (table. 4).

Table (4): Correlation between serum IL-23 level, clinical and laboratory parameters of RA patients.

\begin{tabular}{lll}
\hline \multirow{2}{*}{ Variable } & \multicolumn{2}{c}{ IL-23 level } \\
\cline { 2 - 3 } & \multicolumn{1}{c}{$\mathbf{r}$} & \multicolumn{1}{c}{$\mathbf{P}$} \\
\hline Age & 0.09 & $0.57 \mathrm{NS}$ \\
\hline Disease duration (years) & 0.15 & $0.37 \mathrm{NS}$ \\
\hline Morning stiffness duration & -0.11 & $0.50 \mathrm{NS}$ \\
\hline Swollen Joints & 0.26 & $0.10 \mathrm{NS}$ \\
\hline Tender Joints & 0.22 & $0.18 \mathrm{NS}$ \\
\hline DAS- 28 & $\mathbf{0 . 3 5}$ & $\mathbf{0 . 0 2} *$ \\
\hline CRP (mg/L) & $\mathbf{0 . 3 9}$ & $\mathbf{0 . 0 2} *$ \\
\hline ESR (mm/1h) & 0.45 & $0.004^{* *}$ \\
\hline Hb (gm/dl) & 0.20 & $0.22 \mathrm{NS}$ \\
\hline RF level (IU/ml) & 0.48 & $0.002^{* *}$ \\
\hline Anti CCP level (U/ml) & 0.35 & $0.04^{*}$ \\
\hline
\end{tabular}

$r$ : Spearman correlation coefficient

NS: Non significant $(P>0.05)$

Significant $(P \leq 0.05) \quad * *$ : Highly Significant $(P<0.01)$

Validity of IL-23 in evaluation of disease activity among the $R A$ patients (Table 5). IL-23 at a cut off value of $45(\mathrm{pg} / \mathrm{ml})$, had a sensitivity of $77.8 \%$ and a specificity of $75 \%$ for detection of moderate and high disease activity. . 
Table (5): Validity of IL-23 in evaluation of disease activity among the RA patients

\begin{tabular}{lccccccccc}
\hline Variable & Cutoff & AUC & CI & Sens. & Spec. & $+\mathbf{P V}$ & -PV & Accu. & p-value \\
\hline DAS $\geq 3.2$ & $\geq 45$ & 0.79 & $0.59-0.99$ & 77.8 & 75 & 96.6 & 27.3 & 77.5 & $0.04^{*}$ \\
\hline AUC: Area under curve. & \multicolumn{8}{c}{ CI: Confidence interval. } \\
$+P V:$ positive predictive value. & \multicolumn{1}{c}{-PV: negative predictive value. } & & Accu.:
\end{tabular}

Accuracy.

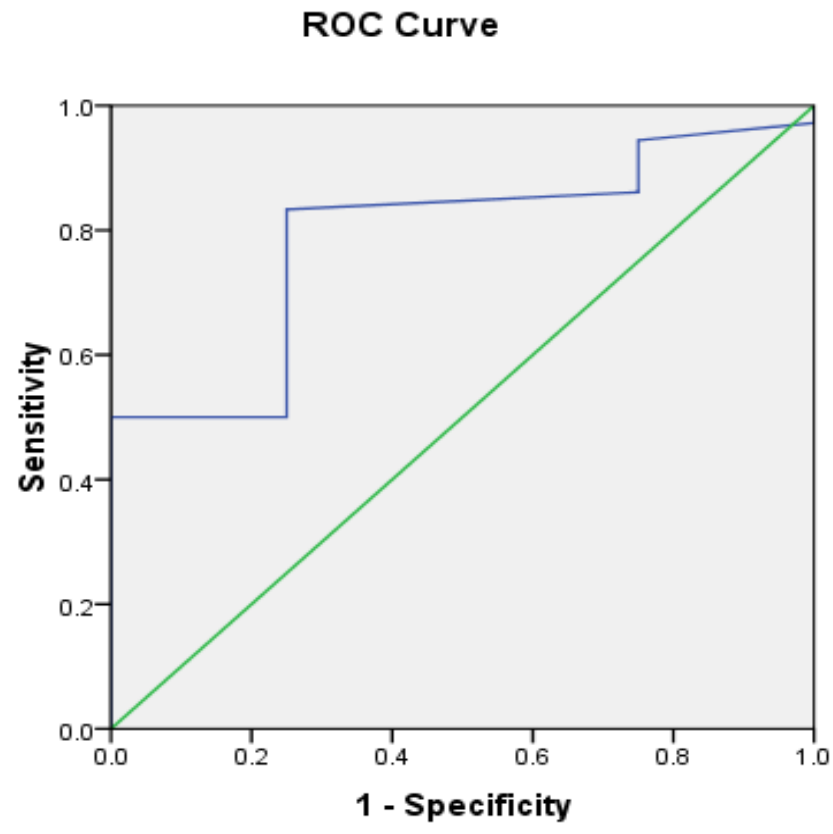

Diagonal segments are produced by ties.

Figure (1): ROC curve for Validity of IL-23 in evaluation of disease activity.

ROC: Receiver operating characteristic curve.

\section{DISCUSSION}

This study was conducted to determine the role of IL-23 in RA as a marker of disease activity in RA patients. Our study showed that the level of IL -23 in RA patients was significantly elevated in comparison to healthy controls. This significant elevation in IL-23 level in RA patients was reported by previous studies ${ }^{[12,13,14]}$. In our study, there was non- significant correlation between each of the age, sex, number of swollen or tender joints and disease duration with IL- 23 level. These results were matched with those of Zaky and El-Nahrery ${ }^{[13]}$, who did not find correlations between IL-23 and clinical data of patients as duration of the disease and the number of affected joints. In contrast to our results, Fadda et al. ${ }^{[12]}$, found significant correlation between serum IL-23 levels and swollen and tender joints, but not with disease duration in RA patients.
One of the main findings of our study is the significant correlation between serum IL23 levels and different grades of DAS-28. Thus, higher serum IL-23 levels indicate higher disease activity in patients with RA. Our results are in agreement with other studies ${ }^{[12,14,16]}$. In contrast with our results, a study by Zaky and El-Nahrery ${ }^{[13]}$ revealed no significant correlation between IL-23 and disease activity measured by DAS-28. However, these contradictory results may be related to differences among the RA patients as regards to medications administered. About the drug treatment, all patients were receiving disease modifying anti-rheumatic drugs (DMARDs). None of them was receiving biologics. IL-23 level was significantly decreased in RA patients, in parallel with the clinical remission in responders after antiTNF- $\alpha$ therapy ${ }^{[15-17]}$. 
In this study, serum levels of IL-23 were significantly correlated with ESR, CRP, RF and anti-CCP antibodies. In agreement with our results, Fadda et al. ${ }^{[12]}$ mentioned that there were significant correlations between IL-23 and ESR, CRP and RF titer. Our results revealed no significant association between physical damage (radiographic joint damage) and IL-23 levels. This finding indicates that serum IL-23 levels correlate with disease activity but not with joint damage.

\section{CONCLUSION}

IL-23 levels were significantly increased in patients with RA compared with healthy controls. Its significant correlation with DAS28 suggested that serum IL-23 level could be a useful marker of disease activity in RA. Direct IL-23 blockade may be an important key in controlling RA disease activity.

\section{REFERENCES}

[1] Glant TT, Mikecz K, Rauch TA. Epigenetics in the pathogenesis of rheumatoid arthritis. BMC Med 2014; 12:35. https://doi.org/10.1186/1741-7015.

[2] Brennan FM, McInnes IB. Evidence that cytokines play a role in rheumatoid arthritis. $\mathbf{J}$ Clin Invest 2008; 118: 3537-45.

[3] Brombacher F, Kastelein R A, Alber G. Novel IL-12 family members shed light on the orchestration of Th1 responses. Trends Immunol 2003; 24: 207-212.

[4] Izcue A, Hue S, Buonocore S. Interleukin-23 restrains regulatory $\mathrm{T}$ cell activity to drive $\mathrm{T}$ cell-dependent colitis. Immunity 2008; 28:559-570.

[5] Gheita TA, El Gazzar II, El-Fishawy HS, Aboul-Ezz MA, Kenawy SA. Involvement of IL-23 in enteropathic arthritis patients with inflammatory bowel disease : preliminary results. Clin Rheumatol 2014; 33(5):707-713.

[6] El HadidiH, Grace BD, Gheita TA, Shaker O. Involvement of IL-23 in psoriasis and psoriatic arthritis patients; possible role in the pathogenesis. J Egypt worn Dermatol Soc 2008; 5(2):70-76.

[7] Gheita TA, Gamal SM, Shaker I, El Fishawy HS, El Sisi R, Shaker OG, et al. Clinical significance of serum interleukin-23 and AlG gene (rs 17375018) polymorphism in Behcets disease: relation to neuro-Behcet, uveitis and disease activity. Joint Bone Spine 2014 ; 29;29 [pii:S1297-319X(14)00252-8].
[8] Aletaha D, Neogi T, Silman AJ, Funovits J, Felson T, Bingham CO, et al. Rheumatoid arthritis classification criteria: an American College of Rheumatology /European League Against Rheumatism collaborative initiative. Arthritis Rheum 2010; 62(9):2569-2581.

[9] Prevoo ML, Hof Van't MA, Kuper HH,Leeuwen van MA, Putte van de LBA, Riel van PLCM. Modified disease activity scores that include twenty-eight-joint counts. Development and validation in a prospective longitudinal study of patients with rheumatoid arthritis. Arthr. Rheum 1995; 38(1): 44-48

[10] Westergren A. Diagnostic tests: the erythrocyte sedimentation rate range and limitations of the technique. Inn Med Kinderheilkunde 1957; 3:20-25.

[11] Van Gaalen FA, Visser H, Huizinga TW. A comparison of the diagnostic accuracy and prognostic value of the first and second anticyclic citrullinated peptides (CCP1 and CCP2) autoantibody tests for rheumatoid arthritis. Ann Rheum Dis 2005; 64:1510-12.

[12] Fadda S H, Abd Elazeem M, Mohammed R A et al. Correlation between disease activity and serum interleukin-23in rheumatoid arthritis. Egyptian Rheumatology \& Rehabilitation 2017; 44:118-124.

[13] Zaky DS, El-Nahrery M. Role of interleukin23 as a biomarker in rheumatoid arthritis patients and its correlation with disease activity. Int Immuno pharmacol 2016; 31:105-108.

[14] Al Fadl E M, Fattouh M, Allam M. High IL23 level is a Marker of Disease Activity in RA. The Egyptian Journal of Immunology 2013; 20 (2):85-92.

[15] Kageyama $Y$, Ichikawa $T$, Nagafusa $T$, Torikai E, Shimazu M, Nagano A et al. Etanerecept reduces the serum levels of interleukin-23 and macrophage inflammatory protein-3 alpha in patients with rheumatoid arthritis. Rheumatol Int 2010; 28:137-143.

[16] Dalila A S, Said M, Shaharir S S, Asrul AW, Low SF, et al. Interleukin-23 and its correlation with disease activity, joint damage, and functional disability in rheumatoid arthritis. Kaohsiung Journal of Medical Sciences 2014; XX, 1-6.

[17] Guo YY, Nai-zhi WA, Shuai ZH,et al. Increased interleukin-23 is associated with increased disease activity in patients with rheumatoid arthritis. Chin Med J 2013; 126:850-854. 